\title{
The Society of Hospital Medicine's Commitment to Increasing Academic Representation for Women and Underrepresented Groups in Medicine: A Good Start
}

\author{
Sarah Fletcher', Shannon M Ruzycki, MD, MPH'2,3*
}

${ }^{1}$ Innovation Support Unit, Department of Family Practice, University of British Columbia, Vancouver, British Columbia, Canada; ${ }^{2}$ Department of Medicine, Cumming School of Medicine, University of Calgary, Calgary, Alberta, Canada; ${ }^{3}$ Department of Community Health Sciences, Cumming School of Medicine, University of Calgary, Calgary, Alberta, Canada.

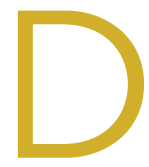

ocumentation of gender-based disparities in medicine often focus on lower numbers of women in prominent positions as evidence of inequality and inequity; examples include lower proportion of women physicians as conference speakers, ${ }^{1}$ first and last authors of manuscripts, ${ }^{2}$ invited editorials, ${ }^{3}$ award recipients, ${ }^{4}$ grant recipients, ${ }^{5}$ medical society leadership, ${ }^{6}$ editorial boards, ${ }^{7}$ and presenters at grand rounds. ${ }^{8}$ Notably, these disparities are likely greater for intersectional physicians, who experience bias through multiple lenses of disadvantage. ${ }^{9}$ While the scarcity of women and marginalized populations in leadership roles in medicine provides convincing evidence that inequality exists, the underrepresentation of women and other marginalized physicians in prominent positions is also a cause of continued disparity. Fewer academic opportunities for women physicians and other underrepresented physician groups in medicine may perpetuate slower career advancement ${ }^{10}$ and contribute to less availability of mentors and sponsors. ${ }^{11}$ Less obviously, underrepresentation also unintentionally and explicitly signals to junior faculty from marginalized groups that they are not welcome and are unlikely to be successful. 9,12

Improving representation of women in other fields has been demonstrated to reduce implicit and explicit sexism. ${ }^{13,14}$ Increasing diversity in academic leadership is likely to further improve diversity at all levels, 9,15 which may in turn reduce gaps in health outcomes seen for marginalized patients. ${ }^{16-18}$ Measuring and eliminating bias that disadvantages underrepresented physicians in academic opportunities is a moral imperative for institutions and organizations. For this reason, the Society of Hospital Medicine (SHM) has been attempting to address this issue within its organizational structure, publications, and conference presenters. ${ }^{19}$

The first step for an organization that aims to increase representation of women and other marginalized groups in medicine is to assess the current representation of leadership and opportunities. ${ }^{20}$ If data are available, this review

*Corresponding Author: Shannon M. Ruzycki; Email: Shannon.Ruzycki@ucalgary.ca; Telephone: 403-210-7370.

Received: March 3, 2020; Accepted: March 4, 2020

๑) 2020 Society of Hospital Medicine DOI 10.12788/jhm.3407 should include intersectional measurement of other axes of discrimination. Rapid analysis of large data sets of names is feasible using freely available computer algorithms, for example. ${ }^{21}$ Only once a baseline understanding of representation within an organization is established can identification of goals and areas of improvement and evaluation of efforts to increase representation begin. Reporting this data to the organization's membership should be undertaken to increase the accountability of leadership to reduce gaps. This work is currently underway at the Journal of Hospital Medicine and within the Society of Hospital Medicine. ${ }^{19}$

This month's issue of the Journal of Hospital Medicine includes an article written by Northcutt, et al that describes one such attempt, focusing on representation of conference speakers at SHM's Annual Meeting. In this study, authors performed a pre- and postintervention analysis of an open call system for selecting didactic speakers for the SHM Annual Meeting. The open call system, implemented for the 2019 SHM Annual Meeting, invited all members to apply for a didactic session. The planning committee then utilized a standardized evaluation form to determine the final speaker list. In previous years, didactic speakers did not apply but were invited and were not formally evaluated. Northcutt et al report that this intervention was associated with a significant increase in the proportion of women conference speakers. ${ }^{22}$

The Northcutt article and the open call and evaluation system is one example of an intentional adjustment to the speaker selection process aimed at recruiting more diverse presenters. Other examples of intentional efforts to increase diversity within conferences include using curated lists designed to improve representation or contacting other national organizations for recommendations. ${ }^{20}$ Efforts such as these are necessary because men in medicine are more likely to volunteer for prominent positions than women, ${ }^{23}$ meaning that any system of recruitment or allocation of academic opportunities that relies on self-promotion is likely to perpetuate underrepresentation. Using pre-existing speakers list or previous programs will also support ongoing disparities, because men have traditionally represented the majority of speakers.

Of course, conferences are an important and public representation of a society, but are only the starting point for working towards equity within a large organization such as SHM. Similar efforts must be directed towards authorship in 
SHM publications, representation on editorial boards, society leadership and employment opportunities. Once organizations have an established baseline around publications, leadership recruitment, and employment representation, a review of recruitment policies (for articles, speakers, leaders, and employees) should then be conducted, looking for areas that lead to bias.

Planning committees, editorial boards, and society leadership groups should also intentionally increase their own diversity, as increasing the proportion of women on a convening committee has been demonstrated to increase the number of invited women speakers. ${ }^{15,24}$ In addition, committees can adopt a mandate to increase diversity in invited speakers, editorials, and authorship; for example, direct instruction to avoid all-male panels led a conference planning committee to invite more women and increased the numbers of women speakers. ${ }^{25} \mathrm{~A}$ speaker, authorship, or editorial policy that emphasizes diversity and inclusion should be developed and made available to the organization's membership. ${ }^{26}$

Finally, there is evidence that implicit bias training for editorial boards and conference planning committees may be effective. ${ }^{27}$ Implicit bias training emphasizes that judgements

\section{References}

1. Ruzycki SM, Fletcher S, Earp M, Bharwani A, Lithgow KC. Trends in the proportion of female speakers at medical conferences in the United States and in Canada, 2007 to 2017. JAMA Netw Open. 2019;2(4):e192103. https://doi. org/ 10.1001/jamanetworkopen.2019.2103.

2. Penn CA, Ebott JA, Larach DB, Hesson AM, Waljee JF, Larach MG. The gender authorship gap in gynecologic oncology research. Gynecol Oncol Rep. 2019;29:83-84. https://doi.org/10.1016/j.gore.2019.07.011

3. Thomas EG, Jayabalasingham B, Collins T, Geertzen J, Bui C, Dominici F. Gender disparities in invited commentary authorship in 2459 medical journals. JAMA Netw Open. 2019;2(10):e1913682.https://doi.org/10.1001/jamanetworkopen.2019.13682.

4. Silver JK, Slocum CS, Bank AM, et al. Where are the women? The underrepresentation of women physicians among recognition award recipients from medical specialty societies. PM R. 2017;9(8):804-815. https://doi.org/ 10.1016/j.pmrj.2017.06.001

5. Burns KEA, Straus SE, Liu K, Rizv, L, Guyatt G. Gender differences in grant and personnel award funding rates at the Canadian Institute of Health Research based on research content area: a retrospective analysis. PLoS Med. 2019;16(10):e1002935. https://doi.org/ 10.1371/journal.pmed.1002935.

6. Silver JK, Ghalib R, Poorman JA, Al-Assi D, Parangi S, Bhargava H, et al. Analysis of gender equity in leadership of physician-focused medical specialty societies, 2008-2017analysis of gender equity in leadership of physician-focused medical specialty societies, 2008-2017. JAMA Internal Medicine. 2019;179(3):433-435. https://doi.org/10.1001/jamainternmed.2018.5303.

7. Erren TC, Groß JV, Shaw DM, Selle B. Representation of women as authors, reviewers, editors in chief, and editorial board members at 6 general medical journals in 2010 and 2011. JAMA Intern Med. 2014;174(4):633-635. https:// doi.org/ 10.1001/jamainternmed.2013.14760.

8. Files JA, Mayer AP, Ko MG, et al. Speaker introductions at internal medicine grand rounds: forms of address reveal gender bias. J Womens Health (Larchmt). 2017;26(5):413-419. https://doi.org/ 10.1089/jwh.2016.6044.

9. Price EG, Gozu A, Kern DE, et al. The role of cultural diversity climate in recruitment, promotion, and retention of faculty in academic medicine. J Gen Intern Med. 2005;20(7):565-571. https://doi.org/10.1111/j.15251497.2005.0127.x.

10. Carr PL, Gunn CM, Kaplan SA, Raj A, Freund KM. Inadequate progress for women in academic medicine: findings from the National Faculty Study. $J$ Womens Health (Larchmt). 2015;24(3):190-199. https://doi.org/10.1089/ jwh.2014.4848.

11. Farkas AH, Bonifacino E, Turner R, Tilstra SA, Corbelli JA. Mentorship of women in academic medicine: a systematic review. J Gen Intern Med. 2019;34(7):1322-1329. https://doi.org/10.1007/s11606-019-04955-2. of merit and skill are often subjective and based on in-group membership rather than the quality of applicants. ${ }^{9}$ For example, underrepresentation of women at a neuroimmunology conference was not explained by quantity or impact of previous publications, ${ }^{28}$ and evaluation scores for the Society for Hospital Medicine's Annual Meeting have increased as the proportion of women speakers has increased, suggesting that the presence of women presenters was associated with better presentations. To address concerns about how diversity and inclusion efforts may influence the quality of speakers and authors, ${ }^{29}$ objective criteria could be developed in advance of a selection process and candidates should be held to the same standard. ${ }^{30}$ The use of objective evaluation criteria in the selection of conference speakers has also been associated with increasing the proportion of women conference speakers. All in all, SHM's efforts (and Northcutt's work) should be lauded but also recognized as what they are: a good start. Continued vigilance focused on equity is the only way to ensure that the move towards greater representation continues.

Disclosures: The authors have nothing to disclose.

12. Pololi L, Cooper LA, Carr P. Race, disadvantage and faculty experiences in academic medicine. J Gen Intern Med. 2010;25(12):1363-1369. https://doi. org/10.1007/s11606-010-1478-7

13. Beaman $L C R$, Duflo E, Pande R, Topalova P. Powerful women: does exposure reduce bias? Q J Econ. 2009;124(4):1497-1540.

14. Mansbridge J. Should Blacks represent Blacks and women represent women? A contingent "Yes". J Polit. 1999;61(3):628-657. https://doi.org/ https:// doi.org/10.2307/2647821.

15. Lithgow KC, Fletcher, S., Earp, M.E., Bharwani, A., Ruzycki, S.M. Association between the proprtion of women on a conference planning committee and the proportion of women conference speakers at medical conferences. JAMA Netw Open. 2020; In press.

16. Alsan M, Garrick, O., Graziani, G.C. Does diversity matter for health? Experimental evidence from Oakland. National Bureau of Economic Research. 2018.

17. Greenwood BN, Carnahan, S., Huang, L. Patient-physician gender concordance and increased mortality among female heart attack patients. Proc Natl Acad Sci USA. 2018;115(34):8569-8574. https://doi.org/10.1073/ pnas. 1800097115

18. Silver JK, Bean AC, Slocum C, et al. Physician Workforce Disparities and Patient Care: A Narrative Review. Health Equity. 2019;3(1):360-777. https://doi. org/10.1089/heq.2019.0040.

19. Shah SS, Shaughnessy, E.E., Spector, N.D. Leading by example: How medical journals can improve representation in academic medicine. J Hos Med. 2019;14(7):393. https://doi.org/10.12788/jhm.3247.

20. Martin JL. Ten simple rules to achieve conference speaker gender balance. PLoS Comput Biol. 2014;10(11):e1003903. https://doi.org/ 10.1371/journal. pcbi.1003903.

21. Sumner J. The Gender Balance Assessment Tool (GBAT): a web-based tool for estimating gender balance in syllabi and bibliographies. Polit Sci Polit. 2018;2(51):396-400. https://doi.org/10.1017/S1049096517002074.

22. Northcutt N, Papp S, Keniston A, et al; on behalf of the Society of Hospital Medicine Diversity, Equity and Inclusion Special Interest Group. SPEAKers at the National Society of Hospital Medicine Meeting: A Follow-UP Study of Gender Equity for Conference Speakers from 2015 to 2019. The SPEAK Up Study. J Hosp Med. 2020;15(4):XXX-XXX. https://doi.org/10.12788/jhm.3401.

23. Wayne NL, Vermillion M, Uijtdehaage S. Gender differences in leadership amongst first-year medical students in the small-group setting. Acad Med. 2010;85(8):1276-1281. https://doi.org/10.1097/ACM.0b013e3181e5f2ce

24. Casadevall A, Handelsman J. The presence of female conveners correlates with a higher proportion of female speakers at scientific symposia. MBio. 2014;5(1):e00846-13. https://doi.org/10.1128/mBio.00846-13. 
25. Casadevall A. Achieving speaker gender equity at the American Society for Microbiology General Meeting. MBio. 2015;6(4):e01146. https://doi. org/10.1128/mBio.01146-15.

26. Health Nlo. Guidelines for the inclusion of women, minorities, and persons with disabilities in $\mathrm{NIH}$-supported conference grats 2003. https://grants.nih.gov/ grants/guide/notice-files/NOT-OD-03-066.html. Accessed March 12, 2019.

27. Devine PG, Forscher PS, Cox WTL, Kaatz A, Sheridan J, Carnes M. A gender bias habit-breaking intervention led to increased hiring of female faculty in STEMM departments. J Exp Soc Psychol. 2017;73:211-215. https://doi. org/10.1016/j.jesp.2017.07.002
28. Klein RS, Voskuhl, R, Segal BM, et al. Speaking out about gender imbalance in invited speakers improves diversity. Nat Immunol. 201;18(5):475-478. https:// doi.org/10.1038/ni.3707.

29. Borrero-Mejias C, Starling AJ, Burch R, Loder E. Ten (Eleven) things not to say to your female colleagues. Headache. 2019;59(10):1846-1854. https://doi. org/10.1111/head.13647

30. Bandiera G, Abrahams C, Ruetalo M, Hanson MD, Nickell L, Spadafora S. Identifying and promoting best practices in residency application and selection in a complex academic health network. Acad Med. 2015;90(12):15941601. https://doi.org/10.1097/ACM.0000000000000954. 